\title{
Gettering of transition metals in high- performance multicrystalline silicon by silicon nitride films and phosphorus diffusion ${ }^{\circledR}$
}

Cite as: J. Appl. Phys. 125, 043103 (2019); https://doi.org/10.1063/1.5050566

Submitted: 01 August 2018 . Accepted: 09 January 2019. Published Online: 28 January 2019

AnYao Liu (D), Chang Sun (D), Hang Cheong Sio, Xinyu Zhang, Hao Jin, and Daniel Macdonald

\section{COLLECTIONS}

EP This paper was selected as an Editor's Pick
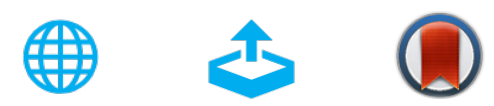

\section{ARTICLES YOU MAY BE INTERESTED IN}

Design of semiconductor surface pits for fabrication of regular arrays of quantum dots and nanorings

Journal of Applied Physics 125, 045303 (2019); https://doi.org/10.1063/1.5064807

Neuromorphic thermal-electric circuits based on phase-change $\mathrm{VO}_{2}$ thin-film memristor elements

Journal of Applied Physics 125, 044501 (2019); https://doi.org/10.1063/1.5037990

Thermoelectric properties of topological insulator lanthanum phosphide via first-principles study

Journal of Applied Physics 125, 045107 (2019); https://doi.org/10.1063/1.5043170

\section{Applied Physics Reviews}

Now accepting original research 


\title{
Gettering of transition metals in high-performance multicrystalline silicon by silicon nitride films and phosphorus diffusion
}

\author{
Cite as: J. Appl. Phys. 125, 043103 (2019); doi: 10.1063/1.5050566 \\ Submitted: 1 August 2018 . Accepted: 9 January 2019. \\ Published Online: 28 January 2019
}

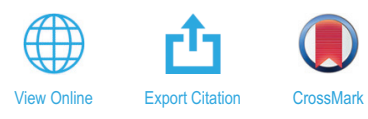

AnYao Liu, ${ }^{1, \text { a) }}$ (1) Chang Sun, ${ }^{7}$ (D) Hang Cheong Sio, ${ }^{7}$ Xinyu Zhang, ${ }^{2}$ Hao Jin, ${ }^{2}$ and Daniel Macdonald ${ }^{1}$

\begin{abstract}
AFFILIATIONS
${ }^{7}$ Research School of Engineering, College of Engineering and Computer Science, The Australian National University, Canberra, Australian Capital Territory 2601, Australia

2Jinko Solar Co., Ltd., Jiangxi 334100, China
\end{abstract}

${ }^{a}$ Author to whom correspondence should be addressed: anyao.liu@anu.edu.au

\begin{abstract}
High-performance multicrystalline silicon ( $\mathrm{HP} \mathrm{mc}-\mathrm{Si}$ ) from directional solidification has become the mainstream industrial material for fabricating mc-Si based solar cells for photovoltaic applications. Transition metal impurities are inherently contained in HP mc-Si during ingot growth, and they are one of the major efficiency-limiting drawbacks. In this work, we investigate the gettering of transition metals $(\mathrm{Cu}, \mathrm{Ni}, \mathrm{Fe}$, and $\mathrm{Cr})$ in $\mathrm{HP} \mathrm{mc}-\mathrm{Si}$ wafers along an industrial-standard p-type $\mathrm{HP}$ mc-Si ingot, via examining the metal concentration and distribution in the near-surface gettering layers using secondary ion mass spectrometry. We applied both conventional phosphorus diffusion gettering and the recently developed silicon nitride (from plasma-enhanced chemical vapour deposition) gettering techniques. Both techniques are shown to remove significant quantities of metals from the silicon wafer bulk to the surface gettering layers. Improvements in the bulk minority carrier lifetimes throughout the ingot height are also observed by lifetime measurements and spatially-resolved photoluminescence imaging. The gettered $\mathrm{Cu}$ and $\mathrm{Ni}$ concentrations, as well as the as-grown dissolved Fe concentrations in the silicon wafer bulk, along the HP mc-Si ingot height are shown to follow a similar concentration profile as the metals in conventional mc-Si ingots.
\end{abstract}

Published under license by AIP Publishing. https://doi.org/10.1063/1.5050566

\section{INTRODUCTION}

Multicrystalline silicon (mc-Si) from directional solidification is a low-cost silicon material that currently accounts for the majority of the silicon solar panels produced worldwide. ${ }^{1}$ The mc-Si material is inherently rich in crystal defects and impurities, which introduce recombination centers in the silicon wafer bulk that limit the conversion efficiency of the solar cells made from these materials.

In recent years, the impact of the crystal defects has been significantly reduced, thanks to the development of the so-called high-performance (HP) mc-Si ingot growth technique, which minimises the propagation of the detrimental dislocation clusters in mc-Si through careful grain size control. ${ }^{2}$ Over the last couple of decades, the mc-Si materials are also becoming increasingly cleaner from impurities, particularly metallic impurities, due to better contamination control in the crucible, crucible lining and feedstock, as well as benefiting from an improved understanding of the impurity contamination sources in mc-Si ingot growth processes. ${ }^{3-7}$ As a combined result, the current state-of-the-art industrial HP mc-Si materials are of much better quality than those used 5-10 years ago. This is reflected in the higher and more tightly distributed solar cell efficiencies made from such materials. ${ }^{1,2}$

Several groups have reported on the responses of HP mc-Si wafers to the gettering and hydrogenation steps used in solar cell fabrication, mainly from the perspectives of observing changes in the bulk carrier lifetime and recombination activity of the crystal defects. ${ }^{8-12}$ Stokkan et al. characterised the total metal concentrations in a number of laboratory-scale HP mc-Si ingots via Neutral Activation Analysis (NAA). ${ }^{3}$ The same group also used secondary ion mass spectrometry (SIMS) to assess the metal concentrations in dislocation clusters, although 
only Ni could be identified above the detection limit (DL). ${ }^{11}$ The concentration and distribution of dissolved, interstitial $\mathrm{Fe}$ $\left(\mathrm{Fe}_{i}\right)$ in laboratory-scale HP mc-Si ingots were reported in Refs. 13 and 14.

This work will focus on the gettering of metallic impurities in HP mc-Si. In particular, we will examine the concentration and distribution of some of the $3 \mathrm{~d}$ transition metals that are gettered along a typical industrial-standard p-type HP mc-Si ingot. SIMS is used to measure $\mathrm{Cu}, \mathrm{Ni}, \mathrm{Fe}$, and $\mathrm{Cr}$ depth profiles in surface gettering layers, where the gettered metals are concentrated by a few orders of magnitude compared to the silicon wafer bulk, allowing SIMS measurements above the detection limit. This is similar to the approach used by Bentzen et al. for conventional mc-Si wafers. ${ }^{15}$ Intra-grain regions of the HP mc-Si wafers will be examined, as a recent study on laboratory-scale HP mc-Si shows that the intra-grain metal concentrations agree better with the average concentrations in $\mathrm{cm}$-sized mc-Si blocks. ${ }^{3}$ In addition, probing the intra-grain regions minimises the impact of internal gettering (i.e., gettering by grain boundaries and dislocation clusters) on the measurements that focus on the external gettering by surface layers. $\mathrm{Cu}, \mathrm{Ni}, \mathrm{Fe}$, and $\mathrm{Cr}$ are the most commonly found and detrimental metallic impurities in mc-Si. ${ }^{3-5,16-18}$ Although $\mathrm{Cu}$ and Ni are known to be more harmful as precipitates, particularly in mc-Si due to the abundant crystal defects that result in the formation of nano- or micro-precipitates, ${ }^{19}$ gettering of the dissolved $\mathrm{Cu}$ and $\mathrm{Ni}$ atoms at elevated temperatures is certainly beneficial for reducing the subsequent precipitate concentrations during the cooldown.

The surface gettering layers used in this work include a conventional phosphorus diffusion gettering (PDG) layer ${ }^{20}$ and the recently reported silicon nitride $\left(\mathrm{SiN}_{\mathrm{x}}\right)$ thin films from plasma-enhanced chemical vapour deposition (PECVD). ${ }^{21}$ Both the PECVD $\mathrm{SiN}_{\mathrm{x}}$ and atomic layer deposited aluminum oxide dielectric thin films were recently found to have gettering effects for $\mathrm{Fe}$, yet very little is known about the underlying gettering mechanisms. ${ }^{21-24}$ Gettering is known to occur via Fe segregation from the silicon wafer bulk to the surface dielectric films at elevated temperatures (examined up to $\left.900^{\circ} \mathrm{C}\right) .^{21,23,24}$ So far, the gettering effect has only been studied for $\mathrm{Fe}$ in intentionally contaminated float-zone silicon (FZ-Si) wafers. The gettering capacity of PECVD $\mathrm{SiN}_{\mathrm{x}}$ films for other metallic impurities, and its application on mc-Si wafers, will be assessed in this work.

Changes in the silicon wafer bulk before and after gettering are monitored by effective minority carrier lifetime ${ }^{25}$ and spatially-resolved photoluminescence imaging. ${ }^{26}$ Apart from SIMS which measures the total metal concentrations regardless of the chemical state, the dissolved, interstitial Fe concentrations in the silicon wafer bulk are also measured by a lifetimebased $\mathrm{Fe}-\mathrm{B}$ pair dissociation technique. ${ }^{27-29}$ The simulation of diffusion-limited gettering of metals is presented and discussed.

\section{EXPERIMENTAL DETAILS}

The multicrystalline silicon wafers used in this work came from a state-of-the-art industrial G6-scale HP mc-Si ingot, manufactured at Jinko Solar, China. The ingot was p-type boron-doped, and the brick studied was from the center of the ingot away from the crucible walls. The wafers came from four different height positions along the HP mc-Si brick: near-bottom (15\% of the ingot height from the bottom), middle (48\%), near-top (90\%), and top red-zone regions. The boron dopant concentrations were $8.7 \times 10^{15}, 9.4 \times 10^{15}$, $1.2 \times 10^{16}$, and $1.3 \times 10^{16} \mathrm{~cm}^{-3}$, respectively.

Two sister wafers from each ingot height were used in this experiment. The $156 \mathrm{~mm} \times 156 \mathrm{~mm}$ wafers were cut into 9 pieces for ease of handling. The wafers were $185 \pm 10 \mu \mathrm{m}$ thick after saw damage etching in an $\mathrm{HNO}_{3}-\mathrm{HF}$ solution. Two pieces of the sister wafers from each ingot height were then cleaned and coated with PECVD $\mathrm{SiN}_{\mathrm{x}}$ films on both sides. The PECVD process conditions and film properties can be found in Ref. 21. The deposition process is known to cause some impurity gettering effects, ${ }^{21,30}$ as the wafers were held at elevated temperatures (in this case, the sample holder temperature was $\sim 250^{\circ} \mathrm{C}$ for a total of $1 \mathrm{~h}$ ) where some metals are sufficiently mobile to reach the wafer surfaces. The $\operatorname{SiN}_{\mathrm{x}}$ coated samples were then annealed at $700^{\circ} \mathrm{C}$ for 90 min in $\mathrm{N}_{2}$ in a quartz tube furnace. The temperature and time were chosen such that $\mathrm{Cr}$, which has the slowest diffusivity out of the four metals, has sufficient time to reach the surface $\operatorname{SiN}_{\mathrm{x}}$ layers. ${ }^{18}$ One set of the sister wafers from each ingot height was then characterised by SIMS for the metal concentrations in the annealed $\mathrm{SiN}_{\mathrm{x}}$ films and the near-surface silicon regions. The other set of wafers underwent chemical etching to remove the annealed $\mathrm{SiN}_{\mathrm{x}}$ films (the passivation effect of which was degraded after annealing), and a few $\mu \mathrm{m}$ of the silicon wafer surfaces, before being cleaned and re-coated with fresh $\mathrm{SiN}_{\mathrm{x}}$ films on both sides to allow bulk lifetime measurements.

An additional two sister wafer pieces from the same red-zone mc-Si wafers were subjected to phosphorus diffusion after saw damage etching and cleaning. Phosphorus diffusion was carried out in $\mathrm{POCl}_{3}$ in a quartz tube furnace. The $\mathrm{POCl}_{3}$ diffusion was at $810^{\circ} \mathrm{C}$ for a total of $40 \mathrm{~min}$ (including deposition, drive-in, and oxidation), and the temperature ramp-up and ramp-down rate was at $10^{\circ} \mathrm{C} / \mathrm{min}$ from and to $700{ }^{\circ} \mathrm{C}$. This resulted in a sheet resistance of $100 \Omega$ /square for the phosphorus doped silicon surface layer, as measured by a four-point probe. The depth profile of the electrically active phosphorus concentration was measured by electrochemical capacitance-voltage (ECV) profiling, using a WEP Wafer Profile CVP21 instrument. After phosphorus diffusion, one of the sister wafers was characterised by SIMS, which had the phosphosilicate glass (PSG) retained on the wafer surfaces as a surface contamination barrier. The other sister wafer had the PSG and the phosphorus doped silicon layers chemically etched off, and the wafer was then cleaned and coated with PECVD $\mathrm{SiN}_{\mathrm{x}}$ films on both sides to enable bulk lifetime measurements.

Electronic-grade FZ-Si wafers were included in all of the PECVD deposition processes in order to monitor the $\operatorname{SiN}_{x}$ surface passivation quality. The FZ-Si wafers were p-type boron-doped with a dopant concentration of $1.5 \times 10^{16} \mathrm{~cm}^{-3}$ 
and were $200 \mu \mathrm{m}$ thick after etching. Effective surface recombination velocity (SRV) of the as-deposited $\mathrm{SiN}_{\mathrm{x}}$ films was estimated from the carrier lifetime measurements of the FZ-Si control samples, assuming a bulk lifetime that is only limited by Auger and radiative recombination. ${ }^{31,32}$ The extracted SRV was then used to estimate the surface-limited carrier lifetimes $\left(\tau_{\text {surface }}\right)$ for the mc-Si wafers with $\mathrm{SiN}_{\mathrm{x}}$ films. However, as recently pointed out by Grant et al., high purity FZ-Si wafers could contain bulk defects that become recombination active upon thermal processing. ${ }^{33}$ The extracted $\tau_{\text {surface }}$ therefore represents a lower limit of the surfacelimited lifetimes. This probably explains why the middle HP mc-Si sample after gettering has a higher lifetime than the lower limit of the surface lifetime in Sec. III A.

Photoconductance lifetime measurements ${ }^{25}$ and photoluminescence (PL) imaging ${ }^{26}$ were applied to characterise the bulk of the HP mc-Si wafers before and after gettering. The tools used were a WCT-120 Sinton lifetime tester and a BTimaging LIS-R1 PL imager. The calibration method described in Ref. 34 was employed to convert the spatially resolved PL signals to excess minority carrier density images. The interstitial $\mathrm{Fe}$ concentration $\left(\left[\mathrm{Fe}_{i}\right]\right)$ in the silicon wafer bulk, before and after gettering, was also measured by these lifetime-based tools, based on the well-established technique of comparing the effective carrier lifetimes before and after Fe-B pair dissociation via illumination. ${ }^{27-29}$ Error bars in the $\mathrm{Fe}_{i}$ concentrations arose from assuming a $5 \%$ uncertainty in the measured effective carrier lifetimes before and after pair dissociation. The $\left[\mathrm{Fe}_{i}\right]$ detection limit for the given lower limit of $\tau_{\text {surface }}$ and a lifetime uncertainty of $5 \%$ is around $3 \times 10^{9} \mathrm{~cm}^{-3}$.

SIMS depth profiling was used to measure the $\mathrm{Cu}, \mathrm{Ni}, \mathrm{Fe}$, and $\mathrm{Cr}$ concentrations in the near-surface regions, in the $\mathrm{SiN}_{\mathrm{x}} / \mathrm{Si}$ and PSG/P-doped Si/Si samples. The SIMS measurements were conducted by EAG Laboratories. The Si and P raw ion counts were monitored in order to identify the boundaries of the different surface layers. The nominal depth resolution was $\sim 2 \mathrm{~nm} / \mathrm{step}$, although the actual resolution was much larger as the sputtered ions become intermixed during the depth profiling. The metal concentrations were quantified based on implanted calibration standards and relative sensitivity factors.

The SIMS depth profiles typically suffer from surfacerelated measurement artefacts and surface contamination, which manifest themselves as apparent sharp increases toward the wafer surfaces in the top tens of $\mathrm{nm}$, as marked in the SIMS plots below. These regions are disregarded from the analysis. Integrating the SIMS metal profiles allows us to estimate the gettered metal concentrations. An example is shown in Fig. 1, where the shaded region is the area under the curve that the integration took place for the red data curve (Ni gettered to $\mathrm{SiN}_{\mathrm{x}}$ in a top red-zone mc-Si wafer). As shown in Fig. 1, the near-surface region is excluded from the integration, and so is the possible smearing of the surface contamination/artefacts further into the depth profiles, as represented by the fitted curves. In this work, we estimated the smeared surface effect by fitting a power-law curve to

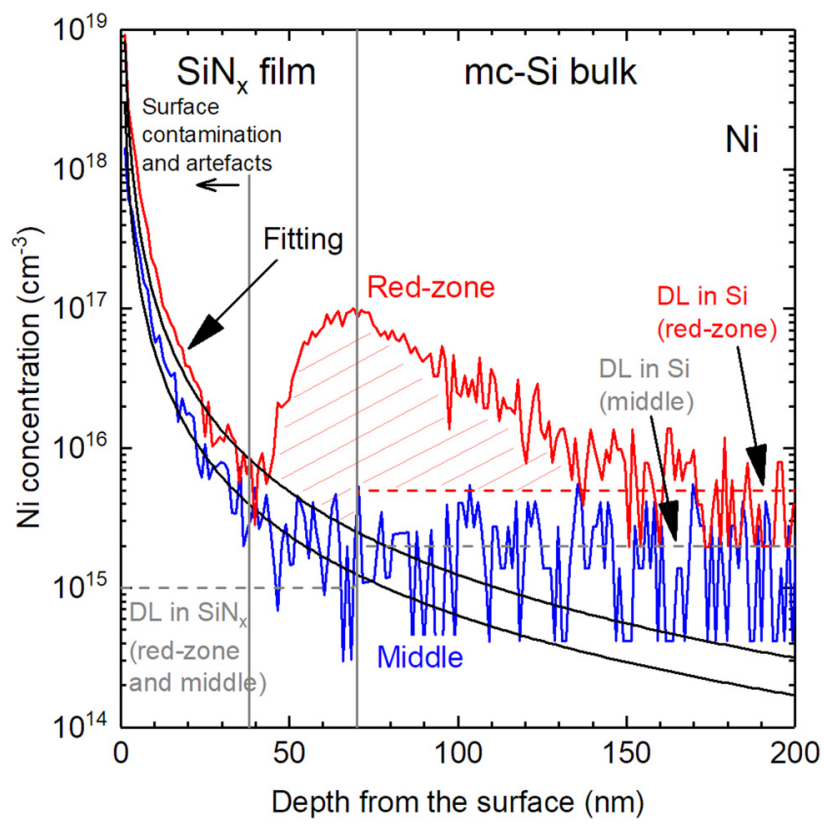

FIG. 1. SIMS Ni profiles in $\mathrm{SiN}_{x} / \mathrm{Si}$ samples $\left(\mathrm{SiN}_{\mathrm{x}}\right.$ gettering $\left.700^{\circ} \mathrm{C} 90 \mathrm{~min}\right)$, where the substrate Si wafers came from the top red-zone and middle positions of an HP mc-Si ingot. The shaded region denotes the integration area for estimating the gettered $\mathrm{Ni}$ concentration of the top red-zone sample.

the near-surface contamination/artefact region and then extrapolated it to deeper into the profile. A power-law curve was chosen as it seems to fit well with the SIMS profiles of the no-Fe control samples from our previous works. ${ }^{21,23}$ The SIMS detection limit (DL) is also considered and subtracted from the data curve (if DL is higher than the fitted "artefact curve"), as shown by the shaded area in Fig. 1. The concentration estimation was integrated until the depth where the signal reaches the detection limit, as the metal-related signal is also smeared deeper into the bulk. The reported error bars in the gettered metal concentrations came from the uncertainty in SIMS calibration factors (provided by EAG Laboratories).

For samples with relatively low gettered metal concentrations, such as the blue data curve in Fig. 1 (Ni gettered to $\mathrm{SiN}_{\mathrm{x}}$ in a middle mc-Si wafer), the uncertainty in estimating the surface smearing effect is too significant to allow an accurate extraction of the gettered metal concentration. These are therefore noted as "below SIMS limit" in Sec. III D.

SIMS was used to probe the intra-grain regions of the HP mc-Si wafers, at least $2 \mathrm{~mm}$ from any grain boundaries or dislocation clusters (except for the near-bottom wafer which has very small grains). As the wafer thickness $(<200 \mu \mathrm{m})$ is much shorter than the distance to crystal defects, external gettering to the wafer surfaces $\left(\mathrm{SiN}_{\mathrm{x}}\right.$ or phosphorus diffused region) is the more dominant effect compared to internal gettering to crystal defects. 


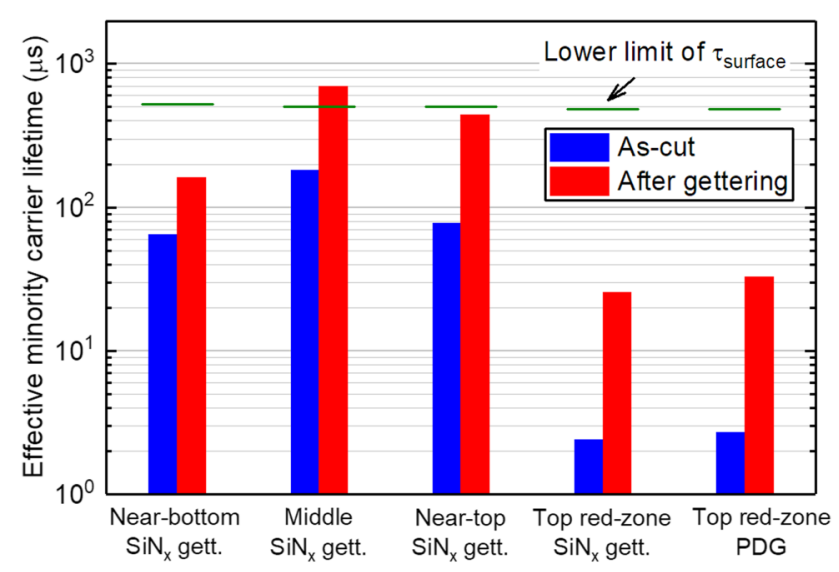

FIG. 2. Average effective minority carrier lifetime before and after gettering, by either annealing with $\mathrm{SiN}_{\mathrm{x}}$ films at $700{ }^{\circ} \mathrm{C}$ for $90 \mathrm{~min}$, or undergoing $\mathrm{POCl}_{3}$ diffusion at $810^{\circ} \mathrm{C}$ for $40 \mathrm{~min}$ (with a ramp-up and cooldown rate of $10^{\circ} \mathrm{C} / \mathrm{min}$ from and to $700^{\circ} \mathrm{C}$ ). All samples had as-deposited PECVD SiN ${ }_{x}$ films on both sides as surface passivation layers. The average lifetimes were from photoconductance measurements at an injection level of $10^{15} \mathrm{~cm}^{-3}$, in the Fe-B dissociated (i.e., isolated $\mathrm{Fe}_{i}$ ) state.

\section{RESULTS AND DISCUSSION}

\section{A. Changes in HP mc-Si wafer bulk}

As shown in Fig. 2, all of the tested HP mc-Si wafers along the ingot height experienced an increase in the effective carrier lifetime after gettering by either phosphorus diffusion or annealing with $\mathrm{SiN}_{\mathrm{x}}$ films. As the FZ-Si controls were found to have largely consistent lifetimes for the different PECVD deposition runs, these changes in the effective lifetimes indicate lifetime improvements in the bulk of the HP mc-Si wafers. However, because of the moderate surface passivation quality, the effective lifetime of some of the HP mc-Si wafers, particularly the middle and near-top wafers, likely becomes almost entirely limited by the surface, making it difficult to accurately extract the lifetime increases in the $\mathrm{mc}-\mathrm{Si}$ wafer bulk. Nevertheless, it appears that the near-bottom HP mc-Si wafer underwent the smallest lifetime improvement, likely due to its high density of recombination active grain boundaries. The microstructure of the HP mc-Si wafers from different ingot positions can be found in Ref. 8, which showed PL images of wafers from the same ingot and from very similar ingot positions.

The lifetime profile with respect to the ingot height is consistent with previous reports. ${ }^{8,11}$ The top red-zone wafers demonstrate the lowest lifetimes both before and after gettering, as they are limited by impurities and defects in the silicon wafer bulk. For these red-zone wafers undergoing either $\mathrm{SiN}_{\mathrm{x}}$ gettering or phosphorus diffusion gettering, similar bulk lifetime improvements are observed in Fig. 2.

An example of the PL images before and after gettering is shown in Fig. 3, for a top red-zone wafer undergoing $\mathrm{SiN}_{\mathrm{x}}$ gettering. Under the same 808-nm laser excitation of $5 \times 10^{16} \mathrm{~cm}^{-2} \mathrm{~s}^{-1}$ (equivalent to approximately 0.2 suns), the light-generated excess minority carrier density $(\Delta n)$ is increased by one order of magnitude after gettering, from an average $\Delta n$ of $2 \times 10^{12} \mathrm{~cm}^{-3}$ in the as-cut state (with only saw damage etching and $\operatorname{SiN}_{\mathrm{x}}$ coating), to $3 \times 10^{13} \mathrm{~cm}^{-3}$ after $\mathrm{SiN}_{\mathrm{x}}$ gettering and re-coating.

For all samples along the mc-Si ingot, hydrogenation of the crystal defects is not observed here after the $700{ }^{\circ} \mathrm{C}$ 90-min $\operatorname{SiN}_{\mathrm{x}}$ annealing treatment. This is likely due to the extended annealing time that caused the onset of dehydrogenation in this case. The $\operatorname{SiN}_{\mathrm{x}}$ film used in this work is
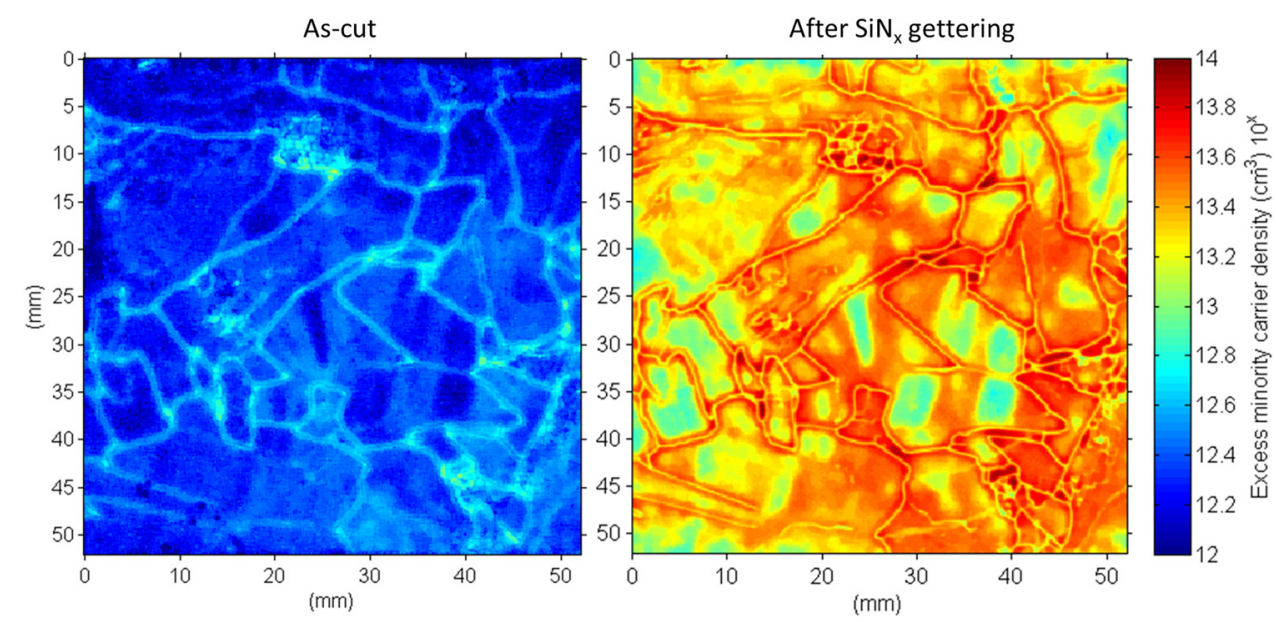

FIG. 3. PL images of the excess minority carrier density in a top red-zone wafer before and after $\mathrm{SiN}_{\mathrm{x}}$ gettering $\left(700^{\circ} \mathrm{C}, 90 \mathrm{~min}\right)$. The wafer had fresh as-deposited PECVD SiN $\mathrm{N}_{\mathrm{x}}$ films on both sides as surface passivation layers. The PL images were taken under the same 808 -nm laser excitation intensity of $5 \times 10^{16} \mathrm{~cm}^{-2} \mathrm{~s}^{-1}(0.2$ suns). Note that the color bar for carrier density is on a logarithmic scale. 
thermally unstable, and its dehydrogenation is also reflected in its much degraded surface passivation quality after annealing. ${ }^{35}$ Our recent study on a range of PECVD $\mathrm{SiN}_{\mathrm{x}}$ films indicates that both thermally stable and unstable films generate similar gettering effects for Fe. ${ }^{22}$ The balance between hydrogenation and dehydrogenation relates to the $\mathrm{SiN}_{\mathrm{x}}$ film properties, ${ }^{35}$ which in turn determine whether or not the benefits of bulk hydrogenation and impurity gettering can be achieved in a single annealing step with the $\mathrm{SiN}_{\mathrm{x}}$ films.

The dissolved, interstitial $\mathrm{Fe}\left(\mathrm{Fe}_{i}\right)$ concentration in the silicon wafer bulk in the as-cut state was found to be reduced by at least an order of magnitude after gettering, regardless of the gettering method or the ingot height position. This is as expected from the known diffusivity of $\mathrm{Fe}$ in silicon, ${ }^{36}$ the gettering effectiveness of phosphorus diffusion for $\mathrm{Fe}{ }^{20,37}$ and that the $\operatorname{SiN}_{\mathrm{x}}$ gettering of $\mathrm{Fe}$ was reported to be largely diffusion-limited below $700^{\circ} \mathrm{C}$. ${ }^{21}$ The bulk $\mathrm{Fe}_{i}$ concentrations will be presented and discussed later in Sec. III D.

\section{B. Metals gettered to the phosphorus diffused surface regions}

The near-surface depth profiles of the metals, as well as the electrically active $P$ dopant concentrations, are shown in Fig. 4 for the phosphorus diffused red-zone HP mc-Si wafer.

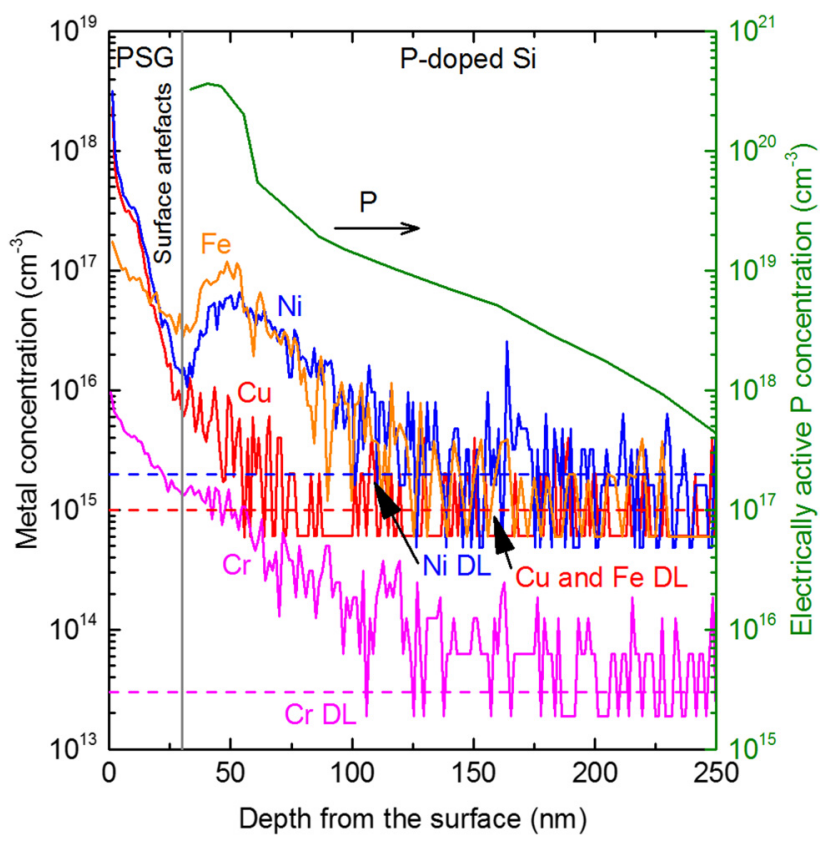

FIG. 4. SIMS depth profiles of the $\mathrm{Cu}, \mathrm{Ni}, \mathrm{Fe}$, and $\mathrm{Cr}$ concentrations in a PSG/ P-doped Si/Si sample. The Si substrate was an HP mc-Si wafer from the top red-zone region of the ingot. An $810^{\circ} \mathrm{C} 40$-min $\mathrm{POCl}_{3}$ diffusion $\left(10^{\circ} \mathrm{C} / \mathrm{min}\right.$ from and to $700^{\circ} \mathrm{C}$ ) was carried out to getter the metals to the surface regions. The SIMS metal detection limits (DL) are included as dashed lines. An ECV depth profile of the electrically active phosphorus dopant concentration is shown as well.
Note that the apparent sharp increases toward the wafer surface in the PSG layer are likely caused by surface contamination and surface-related measurement artefacts.

The phosphorus diffusion condition used in this work represents a typical process used in cell fabrication. As shown in Fig. 4, the phosphorus diffusion results in all four metals, $\mathrm{Cu}, \mathrm{Ni}, \mathrm{Fe}$, and $\mathrm{Cr}$, being gettered to the $\mathrm{P}$ diffused silicon surface regions. The SIMS metal profiles coincide well with the ECV active $P$ dopant profile, which indicates that the metals are preferentially segregated to the heavily $\mathrm{P}$ doped silicon, agreeing with the literature..$^{37,38}$

\section{Metals gettered to the $\operatorname{SiN}_{x}$ surface regions}

Figure 5 presents the near-surface metal profiles of the HP mc-Si wafers which underwent $\mathrm{SiN}_{\mathrm{x}}$ gettering. The $\mathrm{SiN}_{\mathrm{x}} / \mathrm{Si}$ interfaces were identified from monitoring the raw ion counts of the silicon matrix. Again, the sharply increasing metal profiles in the top 30-40 nm, which have similar slopes irrespective of the mc-Si wafer substrates, are due to surface contamination and surface-related measurement artefacts, as marked in the figure.

As shown in Fig. 5, all four metals, $\mathrm{Cu}, \mathrm{Ni}, \mathrm{Fe}$, and $\mathrm{Cr}$, can be measured above the respective detection limit, and some above the possible impact of surface artefacts, at the $\mathrm{SiN}_{\mathrm{x}} / \mathrm{Si}$ interfaces and/or within the bulk of the $\mathrm{SiN}_{\mathrm{x}}$ films, particularly for the top red-zone wafer. This clearly demonstrates the gettering of these metals to the $\mathrm{SiN}_{\mathrm{x}}$ surface regions.

For each metal, the concentration and shape of the profile in the $\mathrm{SiN}_{\mathrm{x}}$ gettering layers exhibit variations along the HP mc-Si ingot height. For $\mathrm{Cu}$ [Fig. 5(a)], while the middle and near-top wafers demonstrate $\mathrm{Cu}$ accumulation only in the bulk of the $\mathrm{SiN}_{\mathrm{x}}$ films, the near-bottom and top red-zone wafers show additional $\mathrm{Cu}$ accumulation at the $\mathrm{SiN}_{\mathrm{x}} / \mathrm{Si}$ interfaces. Ni [Fig. 5(b)] exhibits a clear trend in the concentration of the broad interface peak with respect to the ingot heightthe Ni concentration is highest in the top red-zone wafer, followed by near-top, near-bottom, and middle wafers. In Fig. 5(c), the top red-zone wafer shows a prominent Fe peak near the $\mathrm{SiN}_{\mathrm{x}} / \mathrm{Si}$ interface, while the other three wafers display a much flatter profile in the bulk of the $\operatorname{SiN}_{\mathrm{x}}$ films, some with a smaller amount of Fe near the interfaces as well. Figure 5(d) shows that in the near-bottom, middle, and near-top HP mc-Si wafers, a gradually decreasing profile of $\mathrm{Cr}$ can be found, which may be affected by the surface artefacts; whereas in the top red-zone wafer, $\mathrm{Cr}$ is mostly aggregated in the $\mathrm{SiN}_{\mathrm{x}}$ film near the interface.

Note that the SIMS depth profiles are somewhat smeared by the intermixing of the sputtered ions during measurements, and therefore the metal profiles in Fig. 5 cannot be used to infer the exact width of the gettering regions or layers. The extent of the interface peaks into the silicon wafer substrate is also likely to be attributed by this ion smearing effect.

It is interesting to observe that some of the gettered metal profiles in Fig. 5 differ from the gettered Fe profiles reported in Ref. 21, where Fe, being the only intentional 

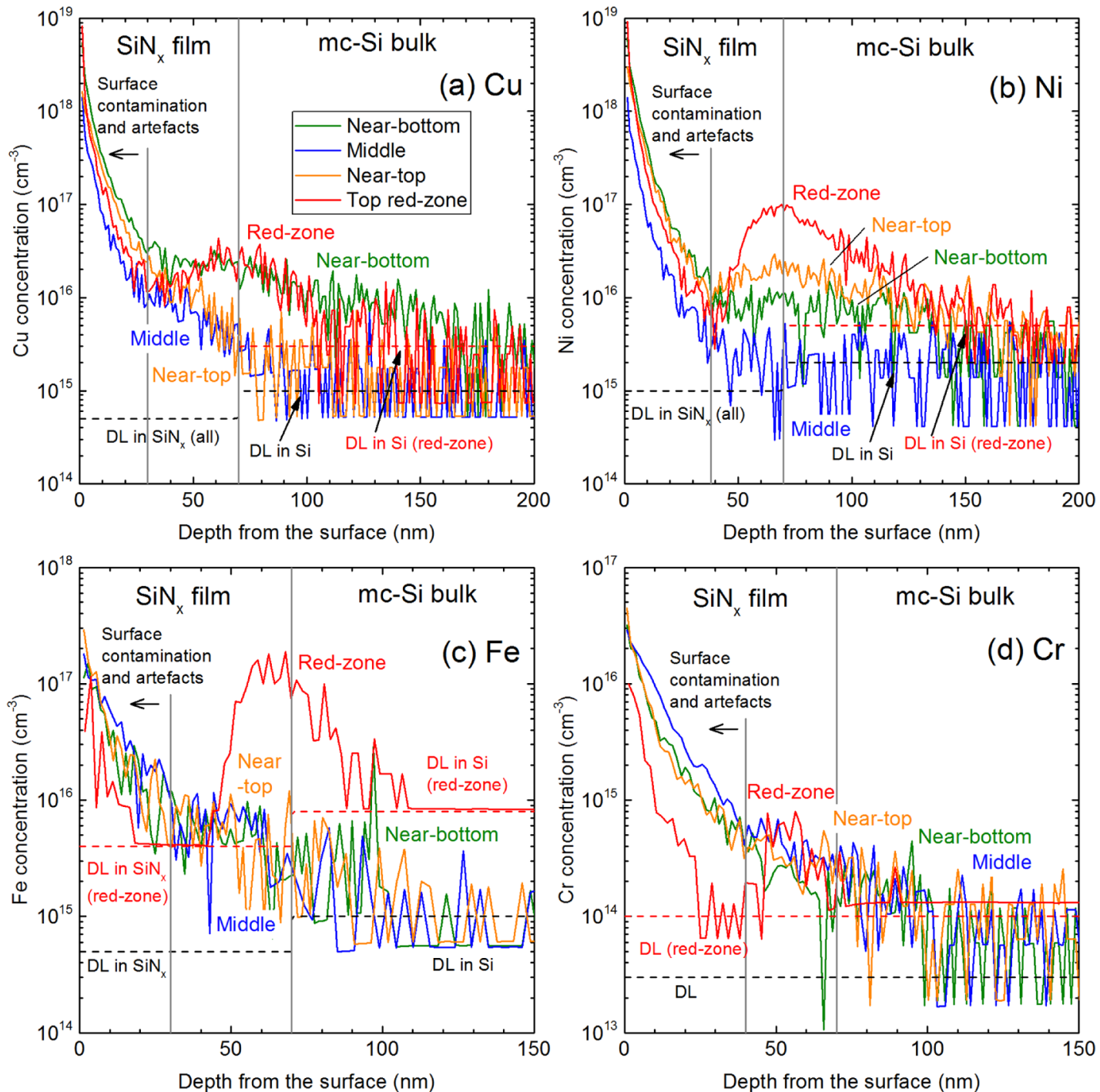

FIG. 5. SIMS depth profiles of the $\mathrm{Cu}, \mathrm{Ni}$, Fe, and $\mathrm{Cr}$ concentrations in $\mathrm{SiN}_{x} / \mathrm{Si}$ samples. The $\mathrm{Si}$ wafer substrates were from near-bottom, middle, near-top, and top red-zone regions of an HP mc-Si brick. After coating with $\mathrm{SiN}_{x}$ films on both sides, the $\mathrm{SiN}_{\mathrm{x}} / \mathrm{Si}$ samples were annealed at $700^{\circ} \mathrm{C}$ for 90 min to enable the gettering of metals to the surface regions. The SIMS metal detection limits (DL) are included as dashed lines.

contaminant in the silicon wafer bulk, was found to be mostly aggregated to the bulk of the $\mathrm{SiN}_{\mathrm{x}}$ films, with a tail into the silicon wafer substrate which is possibly due to the ion smearing effect. However, some of the metal profiles in Fig. 5, particularly the ones with a high metal concentration from the top red-zone region, show obvious peaks at the $\mathrm{SiN}_{\mathrm{x}} / \mathrm{Si}$ interfaces. Interaction of multiple metals may have assisted in the preferential gettering at the interfaces, similar to the co-location of multiple metal clusters during ingot growth.,39 The different profiles may also be caused by the different amounts of metal impurities being gettered to the $\operatorname{SiN}_{\mathrm{x}}$ surface regions. In Ref. $21,9 \times 10^{12} \mathrm{~cm}^{-3}$ or $5 \times 10^{12} \mathrm{~cm}^{-3} \mathrm{Fe}$ atoms were intentionally introduced into clean FZ-Si wafers, whereas the mc-Si wafers, particularly the top red-zone wafers, inherently contain much more impurities of higher concentrations (some of the gettered metal concentrations can be seen in Fig. 6). If there were limited gettering sites in the bulk of the $\mathrm{SiN}_{\mathrm{x}}$ films and the defective $\mathrm{SiN}_{\mathrm{x}} / \mathrm{Si}$ interfaces could allow for more impurity accumulation, a high concentration of impurities may be found near the interface after the saturation in the films. This could also explain the flatter metal profiles in the mc-Si samples with lower metal 
concentrations (for example, the $\mathrm{Ni}, \mathrm{Cu}$, and $\mathrm{Fe}$ profiles of the wafers from near-bottom, near-top, and middle of the ingot), as shown in Fig. 5. Similar SIMS Fe profiles have also been reported in Ref. 40 for the conventional mc-Si wafers after low temperature anneals, where there is no interfacial Fe peak. Further work is required to examine these speculations.

\section{Gettered metal concentrations}

The concentration of metals being gettered from the silicon wafer bulk to the surface regions can be estimated from integrating the SIMS profiles, as detailed in Sec. II. The results are shown in Fig. 6. Those with relatively low concentrations, where the uncertainty in separating signal from surface artefact/contamination is large, are marked as "Below SIMS limit" in Fig. 6. The concentrations of these samples, however, are not necessarily below the lower end of the $y$-axis $\left(10^{10} \mathrm{~cm}^{-3}\right)$ in Fig. 6 . Note that gettering layers were in fact present on both sides of the wafer surfaces, and Fig. 6 presents the gettered metal concentrations in one side of the gettering layers.

Comparing two pieces of a top red-zone wafer undergoing either PDG or $\mathrm{SiN}_{\mathrm{x}}$ gettering, it can be seen from Fig. 6 that similar concentrations of $\mathrm{Ni}$ and $\mathrm{Fe}$ were gettered. The gettered $\mathrm{Cu}$ and $\mathrm{Cr}$ concentrations, on the other hand, are below the SIMS uncertainty range in the phosphorus diffused sample. The difference in the two gettering layers could be simply caused by the large lateral inhomogeneity of the impurity distribution across a top red-zone mc-Si wafer. Nevertheless, the comparison in Fig. 6 confirms that the $\mathrm{SiN}_{\mathrm{x}}$ surface regions can effectively getter metals in addition to $\mathrm{Fe}$, similar to the conventional PDG.
Figure 6 also presents the concentration of metals being gettered to the $\mathrm{SiN}_{\mathrm{x}}$ surface regions for wafers that are from different height positions of the HP mc-Si ingot. The as-cut bulk $\mathrm{Fe}_{i}$ concentrations in these wafers are also shown. The gettered $\mathrm{Ni}$ and $\mathrm{Cu}$ concentrations, as well as the as-cut bulk $\mathrm{Fe}_{i}$, follow the general trend of the metal profiles in a directionally solidified conventional mc-Si ingot-that is, the metal concentration is high in the bottom due to solid-state in-diffusion from the crucible bottom, lowest in the middle, and becomes increasingly higher toward the ingot top because of the combined effect of impurity segregation (i.e., Scheil distribution) and solid-state back-diffusion from the highly contaminated ingot top. ${ }^{4}$ As it is not possible to track the same grain throughout the ingot height, the comparison of the gettered metal concentrations along the ingot is affected, to some extent, by the lateral inhomogeneity across the examined $\mathrm{mc}-\mathrm{Si}$ wafers.

Note that the gettered metal concentration reported here is a fraction, possibly a large fraction, ${ }^{41}$ of the total metal concentration in silicon, as metal precipitates and compounds may not fully dissolve and diffuse to the gettering sites during the process. Nevertheless, the trend of the gettered metal concentrations and the as-cut bulk $\mathrm{Fe}_{i}$ concentrations suggests that the contamination sources and incorporation mechanisms likely remain unchanged for the $\mathrm{HP} \mathrm{mc}-\mathrm{Si}$ ingots. This agrees with the literature that the crucible and crucible coating, rather than the crystallisation technique, are identified as the most important contamination sources in directionally solidified $\mathrm{mc}-\mathrm{Si}^{3,42,43}$

Although the gettered metal concentrations should not be directly compared with the total metal concentrations reported in the literature ${ }^{3-5,41}$ a comparison can be made on the as-cut bulk $\mathrm{Fe}_{i}$ concentrations. The p-type $\mathrm{HP}$ mc-Si

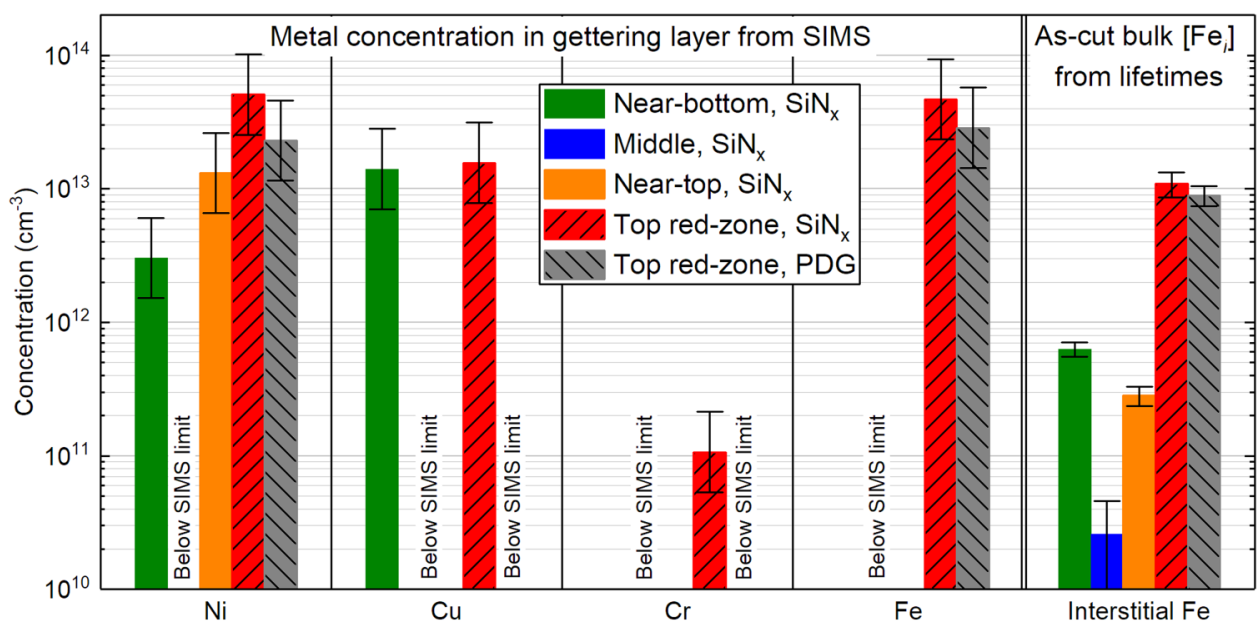

FIG. 6. Concentrations of $\mathrm{Ni}, \mathrm{Cu}, \mathrm{Cr}$, and $\mathrm{Fe}$ that are gettered to the surface layer of either $\mathrm{SiN}_{\mathrm{x}}\left(700^{\circ} \mathrm{C} 90 \mathrm{~min}\right)$ or phosphorus diffused silicon $\left(\mathrm{POCl}_{3}\right.$ diffusion $810^{\circ} \mathrm{C}$ $40 \mathrm{~min}$ ), from integrating SIMS profiles. The interstitial Fe concentrations in the silicon wafer bulk in the as-cut state prior to gettering, as measured from carrier lifetimes, are also shown. The silicon wafers come different positions along an HP mc-Si ingot. 
wafers studied here are shown to have lower $\mathrm{Fe}_{i}$ concentrations throughout the ingot height as compared to the conventional mc-Si wafers in Refs. 4, 40, and 44. This is a good indication of the much-improved impurity control in this new generation mc-Si material.

For the top red-zone wafers which have unambiguous SIMS signals, Fig. 6 also shows that the concentrations of Fe being gettered to the surface regions $\left(\mathrm{SiN}_{\mathrm{x}}\right.$ or $\left.\mathrm{PDG}\right)$ are higher than the corresponding as-cut bulk $\mathrm{Fe}_{i}$ concentrations prior to gettering. Although we cannot entirely rule out the contribution of other metal-related complexes and defects (which might exist in silicon according to the theoretical calculations ${ }^{45,46}$ ) to the gettered Fe concentrations, Fe precipitate dissolution and subsequent gettering seems to be the more likely explanation in $\mathrm{mc}-\mathrm{Si}$ from numerous experimental reports. ${ }^{12,47-50}$

\section{E. Modeling diffusion-limited gettering of metals}

Figure 7 models the time and temperature required to getter $99 \%$ of the initially dissolved, mobile 3d transition metals in silicon, assuming a typical HP mc-Si solar cell thickness of $170 \mu \mathrm{m}$, and that both wafer surfaces act as infinite gettering sites. ${ }^{51}$ That is, the gettering process is assumed to be only limited by the diffusion of metals in silicon. For Ni, $\mathrm{Co}, \mathrm{Mn}$, and $\mathrm{Cr}$, the available diffusivity parameters were derived from data at temperatures above $900^{\circ} \mathrm{C}^{18}$ or $665^{\circ} \mathrm{C}$ (Ni), ${ }^{52}$ and hence the extrapolated diffusivities are used for modeling, as denoted by dashed lines in Fig. 7. The diffusivity parameters of $\mathrm{Cu}$ and $\mathrm{Fe}$ are from Refs. 19 and 36.

The diffusion-limited gettering assumption means that the simulation in Fig. 7 represents the minimum time required to getter $99 \%$ of the dissolved metal at a given temperature, as the gettering processes are in some cases also limited by the gettering reactions. For instance, the gettering kinetics of Fe by PECVD $\mathrm{SiN}_{\mathrm{x}}$ films were found to be largely limited by the Fe diffusivity at temperatures below $700^{\circ} \mathrm{C}$, and at higher temperatures of $800^{\circ} \mathrm{C}-900^{\circ} \mathrm{C}$, the kinetics become reaction-limited. ${ }^{21}$ It is uncertain at this stage whether the $\mathrm{SiN}_{\mathrm{x}}$ gettering of other metals, especially the fast-diffusing metals, follows similar diffusion-limited kinetics at moderate or low temperatures. The gettering reaction at PDG layers depends on the diffusion parameters, e.g., the dopant concentration, oxygen, vacancy injection, etc, and the gettering kinetics also change during the dynamic thermal diffusion processes. $^{37,38}$ Furthermore, in mc-Si materials, precipitate dissolution and metal interaction with crystal defects affect the final gettering effects as well.

Nevertheless, the simulation in Fig. 7 suggests that the fast-diffusing metals of $\mathrm{Cu}, \mathrm{Ni}$, and $\mathrm{Co}$ have the potential to be effectively gettered within seconds or tens of seconds at typical contact firing temperatures $\left(700-850^{\circ} \mathrm{C}\right)$, or even at lower temperatures if they were not yet precipitated. $\mathrm{Mn}, \mathrm{Fe}$, and $\mathrm{Cr}$, on the other hand, require minutes to tens of minutes to reach the wafer surfaces at $700-900^{\circ} \mathrm{C}$. Although they could not be completely removed during typical contact firing, their diffusivities are probably not a limiting factor for

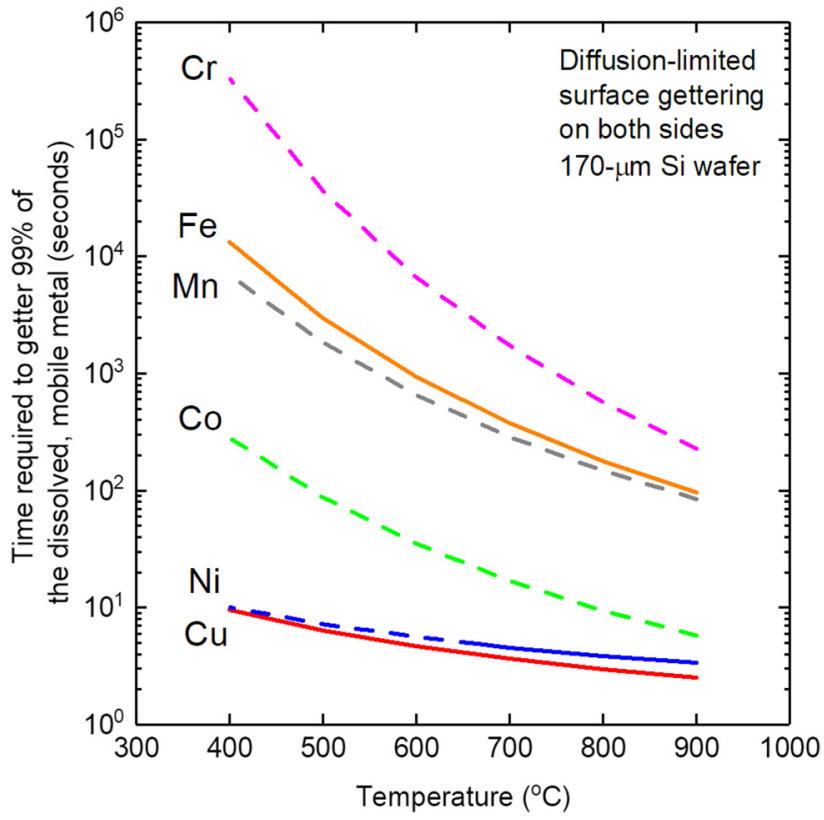

FIG. 7. Modeled time and temperature required to getter $99 \%$ of the dissolved, mobile metal concentrations in a 170- $\mu$ m thick silicon wafer with infinite gettering sites on both wafer surfaces. The dashed lines were modeled based on the extrapolation of the available diffusivity parameters in the literature, ${ }^{18,52}$ whereas the solid lines used the reported diffusivity parameters in Refs. 19, 36, and 52.

gettering by phosphorus diffusions which typically last tens of minutes or even longer.

\section{CONCLUSION}

In summary, this work investigates the concentration and distribution of metallic impurities $(\mathrm{Cu}, \mathrm{Ni}, \mathrm{Fe}$, and $\mathrm{Cr}$ ) in the near-surface gettering layers after either a typical phosphorus diffusion, or a PECVD $\mathrm{SiN}_{\mathrm{x}}$ gettering process, for silicon wafers from different height positions along an industrialstandard p-type HP mc-Si ingot. Metals were found to be aggregated to the surface gettering layers, accompanied by lifetime enhancements in the bulk of the HP mc-Si wafers throughout the ingot height, which demonstrates the continued importance of gettering for this new generation $\mathrm{mc}-\mathrm{Si}$ material. For the top red-zone HP mc-Si wafers compared in this work, the phosphorus diffused silicon regions and the $\mathrm{SiN}_{\mathrm{x}}$ surface layers resulted in similar gettering effects, confirming that metals in addition to Fe could be effectively removed by the PECVD $\mathrm{SiN}_{\mathrm{x}}$ films at elevated temperatures.

The gettered $\mathrm{Cu}$ and $\mathrm{Ni}$ concentrations and the as-cut bulk dissolved Fe concentrations along the HP mc-Si ingot height were revealed to follow a similar trend as the metals in the conventional mc-Si: that is, the metal concentration is high in the top and bottom, and lowest in the middle of the ingot, due to the combined effects of impurity segregation (i.e., Scheil distribution) and solid-state in-diffusions from the 
ingot top and bottom. This suggests that similar contamination sources are still present in this new generation mc-Si material, although the concentration has been substantially reduced.

\section{ACKNOWLEDGMENTS}

This work has been supported by the Australian Renewable Energy Agency (ARENA) through Project No. RND017. The authors A. Y. Liu and H. C. Sio are also supported by the ARENA Australian Centre for Advanced Photovoltaics (ACAP) Postdoctoral Research Fellowship scheme. The authors would like to thank their colleague Dr. Sieu Pheng Phang for assistance with phosphorus diffusion and laser cutting processes.

\section{REFERENCES}

'International Technology Roadmap for Photovoltaic (ITRPV), 2017 Results, 9th ed. (ITRPV, 2018).

${ }^{2}$ Y. M. Yang, A. Yu, B. Hsu, W. C. Hsu, A. Yang, and C. W. Lan, "Development of high-performance multicrystalline silicon for photovoltaic industry," Prog. Photovolt. Res. Appl. 23, 340-351 (2015).

${ }^{3}$ G. Stokkan, M. Di Sabatino, R. Søndenå, M. Juel, A. Autruffe, K. Adamczyk et al., "Impurity control in high performance multicrystalline silicon," Phys. Status Solidi A 214, 1700319 (2017).

${ }^{4}$ D. Macdonald, A. Cuevas, A. Kinomura, Y. Nakano, and L. J. Geerligs, "Transition-metal profiles in a multicrystalline silicon ingot," J. Appl. Phys. 97, 033523 (2005).

${ }^{5}$ A. A. Istratov, T. Buonassisi, R. J. McDonald, A. R. Smith, R. Schindler, J. A. Rand et al., "Metal content of multicrystalline silicon for solar cells and its impact on minority carrier diffusion length," J. Appl. Phys. 94, 6552-6559 (2003).

${ }^{6}$ T. Buonassisi, A. A. Istratov, M. D. Pickett, M. Heuer, J. P. Kalejs, G. Hahn et al., "Chemical natures and distributions of metal impurities in multicrystalline silicon materials," Prog. Photovolt. Res. Appl. 14, 513-531 (2006).

${ }^{7^{T}}$. Buonassisi, A. A. Istratov, M. D. Pickett, J. P. Rakotoniaina, O. Breitenstein, M. A. Marcus et al., "Transition metals in photovoltaicgrade ingot-cast multicrystalline silicon: Assessing the role of impurities in silicon nitride crucible lining material," J. Cryst. Growth 287, 402-407 (2006).

${ }^{8}$ H. C. Sio, S. P. Phang, P. Zheng, Q. Wang, W. Chen, H. Jin et al., "Recombination sources in p-type high performance multicrystalline silicon," Jpn. J. Appl. Phys. 56, 08MB16 (2017).

${ }^{9}$ H. C. Sio and D. Macdonald, "Direct comparison of the electrical properties of multicrystalline silicon materials for solar cells: Conventional p-type, n-type and high performance p-type," Sol. Energy Mater. Sol. Cells 144, 339-346 (2016).

${ }^{10}$ S. Castellanos, K. E. Ekstrøm, A. Autruffe, M. A. Jensen, A. E. Morishige, J. Hofstetter et al., "High-performance and traditional multicrystalline silicon: Comparing gettering responses and lifetime-limiting defects," IEEE J. Photovolt. 6, 632-640 (2016).

${ }^{11}$ K. Adamczyk, R. Søndenå, C. C. You, G. Stokkan, J. Lindroos, M. Rinio et al., "Recombination strength of dislocations in high-performance multicrystalline/quasi-mono hybrid wafers during solar cell processing," Phys. Status Solidi A 215, 1700493 (2018).

${ }^{12} \mathrm{~V}$. Vähänissi, H. S. Laine, Z. Liu, M. Yli-Koski, A. Haarahiltunen, and H. Savin, "Full recovery of red zone in p-type high-performance multicrystalline silicon," Sol. Energy Mater. Sol. Cells 173, 120-127 (2017).

${ }^{13}$ F. Schindler, J. Giesecke, B. Michl, J. Schön, P. Krenckel, S. Riepe et al., "Material limits of multicrystalline silicon from state-of-the-art photoluminescence imaging techniques," Prog. Photovolt. Res. Appl. 25, 499-508 (2017).

${ }^{14}$ J. Schön, P. Krenckel, B. Karches, F. Schindler, J. Giesecke, C. Stieghorst et al., "Improving the material quality of silicon ingots by aluminum gettering during crystal growth," Phys. Status Solidi (RRL) Rapid Res. Lett. 10, 721-724 (2016).

${ }^{15}$ A. Bentzen, A. Holt, R. Kopecek, G. Stokkan, J. S. Christensen, and B. G. Svensson, "Gettering of transition metal impurities during phosphorus emitter diffusion in multicrystalline silicon solar cell processing," J. Appl. Phys. 99, 093509 (2006).

${ }^{16} \mathrm{G}$. Coletti, P. C. P. Bronsveld, G. Hahn, W. Warta, D. Macdonald, B. Ceccaroli et al., "Impact of metal contamination in silicon solar cells," Adv. Funct. Mater. 21, 879-890 (2011).

${ }^{17}$ S. A. McHugo, A. C. Thompson, I. Périchaud, and S. Martinuzzi, "Direct correlation of transition metal impurities and minority carrier recombination in multicrystalline silicon," Appl. Phys. Lett. 72, 3482-3484 (1998).

${ }^{18} \mathrm{~K}$. Graff, Metal Impurities in Silicon-Device Fabrication (Springer, Berlin, 2000).

${ }^{19} \mathrm{~A}$. A. Istratov and E. R. Weber, "Electrical properties and recombination activity of copper, nickel and cobalt in silicon," Appl. Phys. A 66, 123-136 (1998).

${ }^{20}$ S. M. Myers, M. Seibt, and W. Schröter, "Mechanisms of transition-metal gettering in silicon," J. Appl. Phys. 88, 3795-3819 (2000).

${ }^{21}$ A. Y. Liu, C. Sun, V. P. Markevich, A. R. Peaker, J. D. Murphy, and D. Macdonald, "Gettering of interstitial iron in silicon by plasma-enhanced chemical vapour deposited silicon nitride films," J. Appl. Phys. 120, 193103 (2016).

${ }^{22}$ A. Liu, Z. Hameiri, Y. Wan, C. Sun, and D. Macdonald, "Gettering effects of silicon nitride films from various plasma-enhanced chemical vapour deposition conditions," IEEE J. Photovolt. 9, 78-81 (2019).

${ }^{23} \mathrm{~A}$. Y. Liu and D. Macdonald, "Impurity gettering effect of atomic layer deposited aluminium oxide films on silicon wafers," Appl. Phys. Lett. 110, 191604 (2017).

${ }^{24} \mathrm{~A}$. Liu and D. Macdonald, "Impurity gettering by atomic-layer-deposited aluminium oxide films on silicon at contact firing temperatures," Phys. Status Solidi (RRL) Rapid Res. Lett. 12, 1700430 (2018).

${ }^{25}$ R. A. Sinton and A. Cuevas, "Contactless determination of current-voltage characteristics and minority-carrier lifetimes in semiconductors from quasi-steady-state photoconductance data," Appl. Phys. Lett. 69, 2510-2512 (1996).

${ }^{26}$ T. Trupke, R. A. Bardos, M. C. Schubert, and W. Warta, "Photoluminescence imaging of silicon wafers," Appl. Phys. Lett. 89, 044107 (2006).

${ }^{27} \mathrm{G}$. Zoth and W. Bergholz, "A fast, preparation-free method to detect iron in silicon," J. Appl. Phys. 67, 6764-6771 (1990).

${ }^{28}$ D. H. Macdonald, L. J. Geerligs, and A. Azzizi, "Iron detection in crystalline silicon by carrier lifetime measurements for arbitrary injection and doping," J. Appl. Phys. 95, 1021-1028 (2004).

${ }^{29} \mathrm{D}$. Macdonald, J. Tan, and T. Trupke, "Imaging interstitial iron concentrations in boron-doped crystalline silicon using photoluminescence," J. Appl. Phys. 103, 073710 (2008).

${ }^{30} \mathrm{~A}$. Liu, C. Sun, and D. Macdonald, "Hydrogen passivation of interstitial iron in boron-doped multicrystalline silicon during annealing," J. Appl. Phys. 116, 194902 (2014).

${ }^{31}$ A. Richter, S. W. Glunz, F. Werner, J. Schmidt, and A. Cuevas, "Improved quantitative description of Auger recombination in crystalline silicon," Phys. Rev. B 86, 165202 (2012).

${ }^{32}$ H. T. Nguyen, S. C. Baker-Finch, and D. Macdonald, "Temperature dependence of the radiative recombination coefficient in crystalline silicon from spectral photoluminescence," Appl. Phys. Lett. 104, 112105 (2014).

${ }^{33}$ N. E. Grant, V. P. Markevich, J. Mullins, A. R. Peaker, F. Rougieux, D. Macdonald et al., "Permanent annihilation of thermally activated defects which limit the lifetime of float-zone silicon," Phys. Status Solidi A 213, 2844-2849 (2016).

${ }^{34} \mathrm{H}$. Sio, S. Phang, T. Trupke, and D. Macdonald, "An accurate method for calibrating photoluminescence-based lifetime images on multi-crystalline silicon wafers," Sol. Energy Mater. Sol. Cells 131, 77-84 (2014).

${ }^{35}$ J. Hong, W. M. M. Kessels, W. J. Soppe, A. W. Weeber, W. M. Arnoldbik, and M. C. M. van de Sanden, "Influence of the high-temperature "firing" 
step on high-rate plasma deposited silicon nitride films used as bulk passivating antireflection coatings on silicon solar cells," J. Vac. Sci. Technol. B 21, 2123-2132 (2003)

${ }^{36} \mathrm{~A}$. A. Istratov, H. Hieslmair, and E. R. Weber, "Iron and its complexes in silicon," Appl. Phys. A 69, 13-44 (1999).

${ }^{37}$ A. Haarahiltunen, H. Savin, M. Yli-Koski, H. Talvitie, and J. Sinkkonen, "Modeling phosphorus diffusion gettering of iron in single crystal silicon," J. Appl. Phys. 105, 023510 (2009).

38J. Schön, V. Vähänissi, A. Haarahiltunen, M. C. Schubert, W. Warta, and H. Savin, "Main defect reactions behind phosphorus diffusion gettering of iron," J. Appl. Phys. 116, 244503 (2014).

${ }^{39}$ T. Buonassisi, A. A. Istratov, M. Heuer, M. A. Marcus, R. Jonczyk, J. Isenberg et al., "Synchrotron-based investigations of the nature and impact of iron contamination in multicrystalline silicon solar cells," J. Appl. Phys. 97, 074901 (2005).

${ }^{40} \mathrm{M}$. Al-Amin and J. D. Murphy, "Passivation effects on low-temperature gettering in multicrystalline silicon," IEEE J. Photovolt. 7, 68-77 (2017).

${ }^{41}$ D. Macdonald, A. Cuevas, A. Kinomura, and Y. Nakano, "Phosphorus gettering in multicrystalline silicon studied by neutron activation analysis," in Conference Record of the Twenty-Ninth IEEE Photovoltaic Specialists Conference, 2002 (IEEE, 2002), pp. 285-288.

${ }^{42} \mathrm{E}$. Olsen and E. J. Øvrelid, "Silicon nitride coating and crucible-Effects of using upgraded materials in the casting of multicrystalline silicon ingots," Prog. Photovolt. Res. Appl. 16, 93-100 (2008).

${ }^{43}$ R. Kvande, L. Arnberg, and C. Martin, "Influence of crucible and coating quality on the properties of multicrystalline silicon for solar cells," J. Cryst. Growth 311, 765-768 (2009).
${ }^{44}$ A. Y. Liu, Y. C. Fan, and D. Macdonald, "Interstitial iron concentrations across multicrystalline silicon wafers via photoluminescence imaging," Prog. Photovolt. Res. Appl. 19, 649-657 (2011).

${ }^{45}$ M. Sanati, N. G. Szwacki, and S. Estreicher, "Interstitial Fe in Si and its interactions with hydrogen and shallow dopants," Phys. Rev. B 76, 125204 (2007).

${ }^{46}$ S. Estreicher, M. Sanati, and N. G. Szwacki, "Iron in silicon: Interactions with radiation defects, carbon, and oxygen," Phys. Rev. B 77, 125214 (2008).

${ }^{47}$ T. Buonassisi, A. A. Istratov, S. Peters, C. Ballif, J. Isenberg, S. Riepe et al., "Impact of metal silicide precipitate dissolution during rapid thermal processing of multicrystalline silicon solar cells," Appl. Phys. Lett. 87, 121918 (2005).

${ }^{48}$ J. F. Lelièvre, J. Hofstetter, A. Peral, I. Hoces, F. Recart, and C. del Cañizo, "Dissolution and gettering of iron during contact co-firing," Energy Procedia 8, 257-262 (2011).

${ }^{49}$ P. Zhang, H. Väinölä, A. A. Istratov, and E. R. Weber, "Thermal stability of internal gettering of iron in silicon and its impact on optimization of gettering," Appl. Phys. Lett. 83, 4324-4326 (2003).

${ }^{\mathbf{5 0}} \mathrm{S}$. M. Joshi, U. M. Gösele, and T. Y. Tan, "Extended high temperature Al gettering for improvement and homogenization of minority carrier diffusion lengths in multicrystalline Si," Sol. Energy Mater. Sol. Cells 70, 231-238 (2001).

${ }^{51}$ J. D. Murphy and R. J. Falster, "The relaxation behaviour of supersaturated iron in single-crystal silicon at 500 to 750 C," J. Appl. Phys. 112, 113506 (2012). $\mathbf{5 2}^{\mathbf{5}}$. Lindroos, D. P. Fenning, D. J. Backlund, E. Verlage, A. Gorgulla, S. K. Estreicher et al., "Nickel: A very fast diffuser in silicon," J. Appl. Phys. 113, 204906 (2013). 